\section{ON EPIDEMICS,}

\section{STUDIED BY MEANS OF STATISTICS OF DISEASE.*}

\section{By ARTHUR RANSOME, M.A., M.B., Manchester.}

THERE is probably no more legitimate use of the instrument of statistics than its application to the study of epidemic diseases. It may be possible, by individual observation at the bedside of patients, to learn something of the nature of the poisons which originate these diseases-to note the mode in which they affect the organism, and the injuries which they inflict upon it; but no complete knowledge of these wandering disorders can be obtained by this method. When it is required to ascertain the conditions under which epidemics arise, and the laws which govern their progress, an altogether different mode of research is needed. This can only be attained by the accurate observations of many medical men, carefully recorded and collected together. Like the cyclones of the atmosphere, these storms of disease can only be tracked, and the laws of their course discovered, by the combined efforts of many observers, acting under the same regulations, and using instruments of the same uniform standard. That which Captain Maury and Admiral Fitzroy have done for meteorology and navigation, needs now to be attempted on behalf of medical science.

More than thirty years ago, Dr. Graves, speaking of epidemic and endemic diseases, says: "Were the rulers of civilised nations to bring into active operation a number of institutions which, discharging the functions of medical observatories, should observe and record the appearance and symptoms of epidemics, many curious facts relating to their origin and progress would soon be brought to light, and we might then perhaps be enabled to arrive at a knowledge of some general laws respecting their motions." This wish of a great physician has probably been echoed by many; but unfortunately, until lately, with very little result.

I need not repeat what has been said of the inadequacy of death records to answer the questions awaiting solution; at best, they leave undecided the time and place of the origin of any disease. We have need of a much more sensitive instrument with which to measure the fluctuations of disease, and to search for the causes of their rise and fall. What is required for the study of epidemic disease is a regular record, at sufficiently short intervals, of the number of fresh cases of the diseases occurring within certain definite, but sufficiently extensive, areas of practice; and, coincidently with this, an accurate numerical account of any concurrent circumstances which might seem to have a bearing upon the etiology of disease. There seems now to be some likelihood that these data may be obtained, at any rate in some parts of England.

Since the publication of the metropolitan returns in 1858 , the importance of obtaining similar records from every district of the kingdom has been recognised by many persons. In 1860 , a successful effort to carry out the scheme in that town and its neighbourhood was made by the Manchester and Salford Sanitary Association; and by the aid of all the public medical officers of the district, a very valuable series of weekly returns of disease was obtained, along with very ample meteorological records. It is gratifying to be able to state that these statistics have now been published with the utmost regularity and accuracy, every week for nearly eight years. During the same period, monthly returns of disease from St. Marylebone have been furnished-first, by Dr. R. D. Thompson, and then by Dr. Whitmore; and in 1865 and 1866 , similar records were collected by Dr. R. C. Brown in Preston, and by Dr. Alfred Hill in Birmingham. The combined statistics from these four sources were published during fifteen months in the BRITISH MEDICAL JUURNAL, but were then discontinued for a time on account of their want of complete uniformity. This imperfection is now removed. In 1866 , the powerful organisation of the British Medical Assoclation was brought to bear upon the subject; at their meeting in Leamington, a committee was appointed to consider and report upon the whole subject, and at its instance, a uniform system for the registration of disease was brought forward and adopted at the meeting in Dublin in 1867 . It will no doub be satisfactory to the members to learn that, as one result of their decision, at the commencement of this year, four places-viz., Manchester and Salford, St. Marylebone, Birmingham, and Newcastle-upon-Tynebegan together to produce weekly returns upon the same plan, and with the same schedule of diseases.

I propose, in the present paper, to give a few of the results of these observations, so far as they are applicable to the study of epidemics. For this purpose, I have projected the returns upon the accompanying Charts in the form of curves, which represent the monthly returns of the

* Read before the Public Medicine Section at the Annual Meeting of the British Medical Association in Oxford, August 1868. new cases of each disease coming under treatment at the places named. The returns from Manchester and St. Marylebone are so similar in their extent, that they have been at once compared; but in Preston, the amount of public practice is necessarily much smaller, and the disease schedule was slightly different; I have therefore kept these returns separate (Chart VII).

The following points, which have attracted the notice of epidemiologists, seem to be susceptible of illustration by means of these curves. $I_{2}$ the epidemic constitutions of different years ; 2, contagion; 3 , the wave of epidemic disease ; 4 , the succession of epidemics; 5 , atmospheric influences; 6 , endemic influences; 7 , bodily predisposition to epidemic diseases.

It will not be necessary to give an exact definition of epidemic diseases before considering their natural history. Few physicians now doubt the propriety of the term zymotic at present applied to them. All their phenomena point to their production by the agency of substances which are of the nature of leavens or ferments; some of them, perhaps, living organised germs ; others fluid, like vaccine lymph ; others, again, some form of the ever present "germinal matter." All, however, seem to have a common source of power-a power resembling, in its effects, the mysterious agency of fermentation.

I. Epidemic Constitutions of the Air.-General observation shows that there are seasons especially favourable to the production and growth of the germs of epidemic disease-seasons in which they spread more widely and rapidly than at other times, and carry off a larger proportion of victims. Hippocrates and Galen ascribed this fostering power

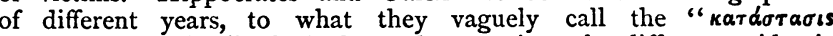

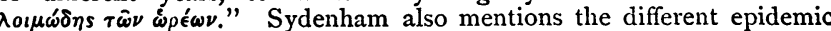
constitutions of different years ; but, with greater exactness, he acknowledges that these constitutions originate "neither in their heat nor their cold, their wet nor their drought ;" they depend rather, he thinks, upon "hidden and inexplicable changes within the bowels of the earth." (Med. Obs., I, 2, and 5.) The rapidity of the course of some epidemics, and the steadiness of their progress in spite of obstacles, have been ascribed to the presence of this mysterious element ; and the appearance of unhealthiness both in animals and plants; and the prevalence of kindred disorders in human beings shortly before the actual outbreak of epidemic disease, have seemed to many to betray the existence of wide-spread general causes.

The Charts show conclusively the presence of an epidemic influence extending over wide areas. A close examination of the curves proves that there is a remarkable correspondence between the curves of different epidemics at Manchester and Salford, and St. Marylebone. (See Charts I to VI). Notwithstanding the distance of these places from one another, their different climates, their various manufactures, and the different occupations and mode of living of their inhabitants, there is a close relation between even the lesser undulations of the waves of their diseases, such as can only be accounted for by the hypothesis of a common cause. (See especially Charts I, IV, and V.) It is evident that we have not yet grasped all the subtle influences at work around us; but we may at once conclude that " neither imperfect sanitary conditions nor simple contagion will account for all the phenomena of the production and propagation of epidemic diseases."*

It is worthy of notice also, that an epidemic influence may be either special or general ; it may be favourable to one disease, as in the whoopingcough epidemic in $186 \mathrm{I}-62$ (Chart III); or it may be a true pestilential atmosphere, and may foster nearly all kinds of epidemic diseases. We have evidence of this latter case in the years $1862-63$, in St. Marylebone and Manchester, when successive storms of whooping-cough (Chart III), measles (Chart I), smallpox (Chart IV), and scarlet fever (Chart v) burst upon the country; and in the year I865, when a similar series of plagues selected the population of Preston as their victims (Chart VII).

Contagion. - The belief in the fostering power of a general epidemic influence is not, however, in the least incompatible with the conviction that epidemics spread chiefly, if not entirely, by means of "contagion" or "infection". The constitution of the air at certain seasons may permit the more free growth of the germs of disease; and thus at these times it may be more readily conveyed from one person to another, and so spread rapidly through a community to all persons susceptible of its influence. Or, again, a predisposing influence may be exerted upon the individual members of a population, rendering a larger number of per. sons liable to receive the poison. The poison itself may in each case be derived from some previously infected person, and most probably is so derived, even in cases of the most isolated character.

The possibility of a spontaneous origin of epidemic diseases, however, is also not precluded by the hypothesis of a general favouring influenoe.

* Diseases in Manchester and St. Marylebone. - Manchester and Salford Sanitary Association. 
It is a doctrine, moreover, which has received very high sanction. Trousseau, in his Clinical Lectures on Contagion, says: "La spontanéité est un fait incontestable dans le développement des maladies même les plus contagieuses ;" and he instances canine madness and "sang de rate" or malignant pustule in support of this statement, and affirms that originally every epidemic must have been generated spontaneously. Many will hesitate, however, before they accept this doctrine. There is, in the first place, some ambiguity about the phrase here employed; and I would point out that, in the cases mentioned by Trousseau, there is no evidence of the spontaneous generation of disease-germs, in the modern sense of the term. Each instance simply proves, that a poison, usually transmitted from one person to another, may, under certain circumstances, be grafted upon the organism from other sources. There is no proof in any case, either that the poison is not living matter or its product, or that it has been generated spontaneously. Surely, also, on other grounds, this is a doctrine to be received with caution.

When we consider, I, the perfectly specific nature of these poisons, 2, the length of time that they retain their power, and 3, the multitude of ways in which they may be conveyed by air, water, clothing, animals, even by insects, we must hesitate before we commit ourselves to the sea of controversy respecting spontaneous generation. It is safer for the present, at any rate, to apply to these disease-germs, as to living beings, the dogma, "Omne vivum e vivo."

I do not venture to assert that our charts throw much light upon questions such as these; but it is interesting to observe, that the course of the more decided epidemics is such as the theory of their spread by contagion would indicate.

The Wave of Epidemic Disease.-I believe that Dr. Farr, in his letter upon the Cattle-Plague, ${ }^{*}$ was one of the first to point out the regularity of the course of most epidemic diseases; and the truth, of his observations is amply borne out by the statistics at our disposal. A glance at the chart will show that the course of each disease, when it becomes epidemic, has a remarkably regular, almost symmetrical arrangement, in its ascent and decline; and this arrangement is most distinct in the course of the most contagious diseases, such as scarlet fever and small-pox. Dr. Farr ascribes the peculiar course of these diseases to their constantly decreasing rate of increase. His theory appears to be, that an epidemic has a certain initial virulence of contagion, but that the intensity of its infecting power diminishes with each transmission; and "that the individuals left are less susceptible of attack, either by constitution or by hygienic conditions, than those destroyed." At each successive period, therefore, of the duration of the disease, it advances at a constantly diminishing speed, until it reaches its highest point, when it suddenly falls at a rate, according to calculation, rather greater than it rose ; but, according to our tables, probably owing to the lack of susceptible persons, it descends at about the same or a slower rate than it spread.

It is difficult to resist the conviction that we have here at least a partial solution of the problem before us, and that it indicates the direction in which to look for further knowledge of the subject.

It may be interesting to note that a strikingly similar course to that indicated on the charts would be taken by an epidemic spreading simply by contagion, and travelling at a certain uniform rate, like a spark smouldering along a piece of tinder; if the area, over which the population is spread, approximated to a square or rectangle, as it does in most of our large towns; the intensity of the action would there be greatest a little after the middle period of the epidemic, and it would sink rather more rapidly than it arose, dying for want of fuel, only retarded in its fall by the constantly increasing quantity of infected fomites it leaves behind it. (See Chart IX.)

The Succession of Epidemics. - The disease-curves display another curious phenomenon-the apparent hostility of one epidemic to another - shown by the successive, not simultaneous appearance of these diseases. This phenomenon was much noticed by Sydenham. In his Description of the Epidemic Constitution of the years $1669-1672$ in London (Med. Obs., Sec. 4, Chap. I), he speaks of one epidemic being driven out by another "ut clavum à clavo," thus using the simile employed by Shakspere, "as one heat another heat expels, or as one nail by strength drives out another."-T Two Gentlemen of Verona, Act II, Scene 4; see

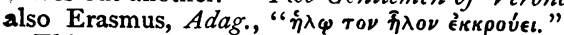

This apparent incompatibility, so to speak, of epidemics is displayed in the two great series of these diseases, at Manchester and St. Marylebone in 1861,1862 , and 1863 , and at Preston in 1865-1866. In the first series, whooping-cough, measles, small pox, and scarlet fever succeeded one another; and in the second, scarlet fever, small-pox, whooping-cough, and measles. In each case as soon as one epidemic

\footnotetext{
* Social Science Revierv. - Chart virr gives Dr. Farr's calculated course of the
cattle plague.
}

had reached its height another took its place. In the words of Sydenham "Ita vicissim mortales lacessunt, prout anni genius et sensibilis aeris temperies huic aut illi magis suffragantur."

The hostility of these diseases to one another is, however, more apparent than real; it is probable that the last quoted sentence gives the clue to the answer. It may depend, as we shall shortly see, chiefly upon the varying influence of the seasons, each disease having a special alliance with the different periods of the year.

Atmospheric Influences. - I will now not enter upon the discussion of the question of the influence of atmospheric changes upon disease. This subject has already been carefully studied by different observers. I will only say, at present, that no one can view the curves drawn upon the charts and compare them with the different months of the year without allowing that each season has its own special burden of sickness to bear, Diarrhoea in Summer, scarlet and typh-fevers in Autumn, measles, whooping-cough, bronchitis and catarrh in Winter and Spring. In the words of Jeremy Taylor, though with different meanings to them, "Calentures and surfeit, cold and agues are the four quarters of the year, and all minister to death." (Holy Dying, Chap. 1.)

It may be remarked also, that if the course of each disease were traced, week by week, instead of month by month, a still closer connec. tion would be discovered between their undulations and the variations of the different meteorological elements. Man's life is still " a breath, servile to all the skiey influences," and his body is the field where

$$
\begin{aligned}
& \text { "Hot, cold, moist, and dry, four champions fierce } \\
& \text { Strive there for mastery, and to battle bring } \\
& \text { Their embryon atoms."-Milton. }
\end{aligned}
$$

Endemic Infuence. - It is not surprising that a fierce word warfare should have been carried on between 'pythogenists' and 'contagionists,' between those who believe that 'filth breeds pestilences,' and those who ascribe the propagation of these diseases solely to a personal or mediate transfer of the specific poison. There are, on the one hand, so many facts showing the subtlety and power of contagion; and, on the other, so many proofs of the evil influence of imperfect sanitary conditions, that neither party need seek far for arguments to support its respective hypothesis. In these discussions, however, it has been too often forgotten, that there are both predisposing and exciting causes of disease, and that, in many instances, these morbid influences must work together in order to bring about an attack of disease; as Dr. Addison has well said-" One blade of the destroying shears is forged at home, without it the other cannot do its work."

The predominating power of contagion in spreading epidemics has already been pointed out, but it is impossible to doubt that endemic influences are also at work, and must materially affect the result. It will be seen from the charts of the diseases of Manchester and London, that certain classes of disease are almost always more prevalent at one place than at the other. Affections of the air-passages (Chart II), bronchitis and catarrh, pleurisy and pneumonia, are usually much more common in Manchester than in St. Marylebone, and we find accordingly, that measles (Chart I), an exanthematous disease accompanied by catarrh, is rather more prevalent in Manchester than in London. It is interesting to remark, also, that in the two winters, 1860 and 1864 , in which the lung diseases in St. Marylebone mounted above those in Manchester, in those years only does measles become as an epidemic, most prevalent in London.

Whooping-cough, again (Chart III), another zymotic disorder attacking the air-passages, never rises in St. Marylebone to the height it attains in the smoky towns of Manchester and Preston. Diarrhœa and dysentery* (Chart vi) on the other hand, are constantly much more widely spread in London than in Manchester, and we know that in the last two epidemics of cholera, London was very severely visited by this disease, whilst Manchester almost entirely escaped its ravages; a circumstance of no little interest in connection with the question of water supply. It seems highly probable, that if regular returns of disease were made at other places, many interesting and perhaps important conclusions might be drawn respecting the favourite haunts of particular diseases, and the reasons for their prevalence in various parts of the country.

Predisposition to Epidemic Disease.-We are now brought naturally to the consideration of bodily predisposition to epidemic disease. The multitude of fostering influences which have been mentioned makes it very difficult to apportion to each its due share of blame in bringing about the result. It might be supposed that the catalogue of morbific agencies was complete, but a very important ally of disease has yet to be considered; a special aptitude of the organism for the reception of

* They are more fatal, however, in Manchester than in St. Marylebone, especially amongst infants-a fact probably due to several causes; but chiefly, perhaps, to the want in Manchester of mother's care and suitable diet, and to the foul atmosphere in which the children live, produced by the vile system of "privies and ashpits", which prevails in Manchester and Salford. 
the poison. All persons are not equally liable to take infectious disorders, as there are some people who can resist, to a greater or less extent, the action of drugs or poisons, so there are individuals who pass through life without suffering from any epidemic disease, and others who take every complaint. Many of the conditions which modify the tendency to contract disease are well known, such are age, previous infection by the same or kindred diseases, acclimatisation or frequent exposure to infection, pregnancy, and lastly, the singular protection from some of these disorders which seems to be afforded to infants during suckling. But, apart from these circumstances, the proclivity to disease varies in different persons and in the same person at different times. In searching for the causes of this difference, great importance must, I think, be attributed to variations in vital energy from whatever causes they may arise. Unsoundness of the body, whether general or local, is probably a very common source of danger when epidemic diseases are prevalent.

I. Of General Weakness of the Body, as a Predisposing Cause of Disease. - In some seasons of epidemic influence, the virulence of the dose of a zymotic poison may be so great that it will attack, with equal readiness, the strong and weak, the young and old, but in most cases we may be tolerably sure that some condition of the body, favourable to the disease, has facilitated its attack; that treachery has been at work within the camp; that the weakness of the body has been the opportunity of the disease. I would especially refer to typhus fever as the disease whose history shows most clearly the truth of this statement. The most powerful predisposing causes of typhus are, for the most part, simply depressing and weakening influences; starvation and destitution, bodily and mental fatigue, depressing emotions, and intemperance-in the simple but striking words of Hecker (Epidemics, p. 14,) "want, misery, and despair."

There are, however, two statements apparently opposed to this view, which must be noticed in their order. $-\mathbf{I}$. That typhus selects its victims from adults and especially from males; and 2. That there is a larger proportion of deaths to cases amongst the rich than amongst the poor. Nearly all observers concur in admitting the truth of the first of these propositions, but there is more doubt about the accuracy of the second statement, although it has been much insisted upon by Irish physicians. (See Barker and Cheyne, I821, i, 321, 329, 428, 467.)

Dr. Graves says (Clinical Medicine, p. 59): "It is a fact that the maximum of mortality was among the rich, and that those who were most attended to died most speedily. In the epidemics of $1816,1817,1818$, and 1819 , it was found by accurate computation, that the rate of mortality was much higher among the rich than among the poor." On the other hand, Dr. Murchison suggests, that the disparity in the mortality of rich and poor is due to the fact that "the cases of fever among the rich were either typhus or enteric fever, whereas, a larger proportion of the cases among the poor were relapsing fever or febricula, which are rarely fatal."

The difficulty of reconciling the first of these facts with our theory, may also be partly overcome by noticing that it is mainly the mortality, and not the number of cases, which is thus predominant, and Dr. Addison is probably right, when he asserts, with regard to the onset of epidemics generally, that they usually manifest themselves amongst the population in a certain fixed order; "they are first noted in infants, then in children according to their age and strength, then in the weakly and feeble, afterwards in females and the aged, and last of all in the robust and in the middle period of life."

We may also probably set against these statements two physiological truths which will perhaps account for some part of the heavy mortality amongst adults and amongst the better classes:- $\mathbf{I}$. Bernard's observation, that injuries (such as those inflicted in the course of physiological experiment) are resented constitutionally much more seriously by wellbred animals than by those of less perfect breed; and, 2 , the wellknown fact, that persons long accustomed to the action of lowering influences, will resist any sudden attack of disease better than those who have always enjoyed good health. On the whole, then, we cannot but believe, that a weak or unsound state of the body is favourable to the onset of disease. Local weakness, or unsoundness of certain parts of the body, is also not without its influence in producing a tendency to disease.

2. Of local unsoundness of the Body as a predisposing cause of Epidemic disease. - It is a curious and interesting fact that those epidemic disorders, which affect chiefly certain organs of the body, are most common at the season of the year when other non-specific affections of these organs are prevalent, and in those places most favourable to those diseases. Thus, as we have already seen, whooping-cough and measles, (Charts III and I) generally attain their highest prevalence as epidemics, in the winter and spring, when bronchitis and other affections of the air-passages abound. Scarlet fever (Chart $v$ ) nearly always spreads most rapidly in autumn, and occasionally in the spring, and at both these seasons ordinary observation tells us that relaxed and ulcerated throats are most common. Cholera, also, although it may exist in cold weather, has always, in common with diarrhœea, received a powerful impulse from a high temperature (e.g., a weekly mean of over $60^{\circ} \mathrm{Fahr}$.) Fevers of a typhoid character, again, have generally been observed to rise towards the latter end of summer and autumn (Murchison, p. 418), when the liver and bowels are most liable to become deranged; and a high authority states that "circumscribed epidemics, or the ordinary autumnal increase of enteric fever, are often preceded by a great increase of diarrhœa." (Murchison, Continued Fevers, p. 455.) I do not wish to lay more stress upon these coincidences than they deserve, or to draw hasty conclusions from them; but if they should prove to be corroborated by further observations, I would submit that they may perhaps indicate the mode in which these diseases sometimes make their entrance intothe body. It may be that the weakness of particular organs affords an opportunity for the entrance of the epidemic poison which has an "elective affinity" for those organs; and we may be able to meet and ward off attacks of epidemics, by paying especial attention to the condition of those unguarded parts of the body, through which the practicable breach has been made. In this way, possibly, both preventive and eliminative measures during epidemics might be justified, and their use restricted to their proper limits.

I cannot conclude this paper without an urgent appeal to the members of this Association to use their powerful organisation to procure a more general and accurate registration of disease throughout the country. Whatever may be the opinion of this meeting respecting the conclusions which I have ventured to draw from the scanty materials at my com. mand, no one, I think, can doubt that such statistics as those from Manchester and St. Marylebone, if accurately and regularly recorded, are an important aid to the study of epidemics. Only by steadily and carefully tracking these diseases from their origin, following their course from place to place, and noting the influence upon them of surrounding conditions-only by some such method as this can we hope to solve problems, which rank amongst the most interesting in the science of medicine, and the most important to mankind.

\section{CLINICAL MEMORANDA.}

\section{PECULIAR CASE OF POISONING BY OPIUM.}

\section{By John S. Boyd, L.R.C.P., L.R.C.S.Edin., Wigton.}

ON account of the very small number of cases published where death might be attributed to either of two sufficient causes, the following is somewhat remarkable

J. M., aged 32, owing to circumstances which preyed upon his mind, attempted suicide by taking two ounces of laudanum at 7 A.M. After waiting for about twenty minutes, and thinking the poison was not going to take effect, he cut his throat by making a circular incision extending about two-thirds of the way around the neck, dividing in its course, to a slight extent, the thyroid cartilage and the œsophagus, but nof wounding any of the important vessels of the neck. It was on account of the latter attempt that Dr. Tiffen (whose assistant I am) was called to see the patient; the fact of his having taken the laudanum not being then known. He was seen again at II.45, when he continued to progress favourably. I saw him about 5 P.M., ten hours after he had taken the opium, and did not notice any symptoms of poisoning by opium. About 9 P.M., his attendants noticed that he appeared drowsy, and was inclined to sleep. About 4 A.M. next morning, he seemed much worse. Dr. Tiffen saw him shortly afterwards, and found all the appearances of narcotic poisoning. The patient then admitted having taken the laudanum. Strong coffee, brandy, etc., were administered ; but they were of no avail, and he was quite comatose when I saw him at $8 \mathrm{~A}$.M., and remained so until about $\mathbf{I 2 . 3 0}$ P.M., when he died, thirty hours after he had taken the poison.

This case appears to me important for the following reasons.

I. In the absence of a medical man, death would have been attributed to the wound in the throat

2. The case would tend to overthrow the general opinion that the effects of opium must show themselves within an hour after administration.

3. Death was protracted for a longer period than in any other case $I$ have seen recorded.

4. The case affords room for inquiry in regard to the effect of shock postponing the action of the poison. 